\title{
The number of lymphocytes increases in the periprosthetic tissues with increasing time of implant service in non-metal-on-metal total joint arthroplasties: A role of metallic particles?
}

\author{
Martin Hobzaa , David Milde ${ }^{\mathrm{b}}$, Zuzana Slobodovac', Jiri Galloa
}

\begin{abstract}
Background. The objective of the study was to determine the association between periprosthetic concentrations of selected metals and changes induced in periprosthetic tissues (PT).

Methods. PT from 24 patients with metal-on-polyethylene or ceramic-on-polyethylene total joint replacements (TJRs) were examined. Samples underwent histological examination including quantification of cellular populations. Determination of metals was performed according to the published methodology. Results were processed using correlation analysis and Principal Component Analysis (PCA), respectively.

Results. Growing concentration of metals in the PT was found as a function of length of exposure (LoE). Differences in $\mathrm{Ti}, \mathrm{Co}, \mathrm{Cr}$ and $\mathrm{V}$ concentrations (per $\mathrm{a}=0.05$ ) depended on the type of alloy the implants were made from. On the contrary, the implant composition did not reflect in the different numbers of immune cells per 1 high power field, not even in distribution of the membrane type according to the Krenn classification. PCA revealed several clusters in dependence on the LoE, type of the membrane and presence of immune cells. High representation of lymphocytes in the PT was typical for clusters with the longest LoE while a higher representation of neutrophils was typical for a shorter time to reoperation.

Conclusions. Correlation between the LoE and concentrations of metals in its surroundings was demonstrated. However, the tissue image analysis cannot differentiate finer, potentially metal-induced tissue changes. Importantly, the tissues become more similar with an increasing LoE. We draw a conclusion about predominantly non-specific stimulation of the PT jointly by metal and polyethylene particles in non-metal-on-metal TJRs.
\end{abstract}

Key words: total joint replacement, aseptic loosening, metal debris, adverse local tissue response, Krenn classification; lymphocytes

Received: March 13, 2020; Revised: April 8, 2020; Accepted: April 27, 2020; Available online: May 18, 2020

https://doi.org/10.5507/bp.2020.019

(c) 2021 The Authors; https://creativecommons.org/licenses/by/4.0/

${ }^{a}$ Department of Orthopaedics, Faculty of Medicine and Dentistry, Palacky University Olomouc and University Hospital Olomouc, I. P. Pavlova 6, 779 00, Olomouc, Czech Republic

${ }^{b}$ Department of Analytical Chemistry, Faculty of Science, Palacky University Olomouc, 17. listopadu 12, 77146 Olomouc, Czech Republic 'Department of Clinical and Molecular Pathology, Faculty of Medicine and Dentistry, Palacky University Olomouc, Hnevotinska 3, Olomouc, Czech Republic

Corresponding author: Jiri Gallo, e-mail:jiri.gallo@volny.cz

\section{BACKGROUND}

Osteoarthritis of the hip and knee is the most frequent joint disease in adults that can substantially deteriorate the patient's locomotion, independence and self-sufficiency and quality of life. Total hip and knee arthroplasties (THA, TKA) are the accepted standard for treatment of end-stage hip and knee diseases. These implants are designed for long-term use in the human body ${ }^{1}$. There is strong evidence confirming eligibility of total joint arthroplasty in both the localisations to achieve and maintain long-term results ${ }^{2,3}$. On the other hand, it is clear that these interventions have limited survivorship ${ }^{4}$. The reasons for their failure differ at least in part for both anatomical locations. However, the main long-lasting problem is aseptic loosening which means a complete loss of connection between the implant and bone bed ${ }^{5}$. This is a consequence of long-term maladaptation of the implant-bone interface to chronic inflammation induced by prosthetic particles released from THA/TKA in combination with continual mechanical load ${ }^{6,7}$.

A number of studies demonstrate that the surrounding tissues response to prosthetic particles by inflammation of low intensity ${ }^{8}$. This subsequently results in accumulation of stimulated osteoclasts at the border between the bone and implant. A vast body of evidence shows that polyethylene micro- and nanoparticles are the main inductors of debris-induced inflammation ${ }^{5}$. Recently, an attention has been drawn to metallic particles, particularly in relation to premature failure of metal-on-metal (MoM) prostheses $^{9}$. Metals are released from all metallic implants by the mechanism of corrosion or tribocorrosion ${ }^{7,10,11}$. Several studies reported concentrations of selected metals in the periprosthetic tissues, joint fluid, or peripheral blood range ${ }^{12-15}$. The character of the tissue response to the presence of metals has been also studied ${ }^{16-18}$. New terms, such 
as adverse local tissue reactions or adverse reactions to metal debris, have been introduced for more exact communication of the pathologist with an orthopaedic surgeon $^{19,20}$. Hypersensitivity to metallic particles has been also examined in association with premature failure of THA or TKA (ref. ${ }^{21}$ ).

Importantly, it is assumed that non-MoM THAs and TKAs, i.e. metal-on-polyethylene (MoP), ceramic-onpolyethylene $(\mathrm{CoP})$, or ceramic-on-ceramic $(\mathrm{CoC})$, are exposed to a load of metals too. The objective of this study was to examine tissue samples from adjacent places simultaneously for metallic content (i.e. concentration of metals/ $1 \mathrm{~g}$ of the tissue) as well as for the histopathological changes in non-MoM prostheses. We assumed that the structure of the periprosthetic membranes as well as representation of particular immune cells in this membrane would change in reoperated patients with a different time elapsed from the primary surgery and/or metallic load. This analysis should provide a further piece of evidence on the long-term behaviour of metallic implants inside human bodies.

\section{MATERIAL AND METHODS}

\section{Patients}

Between April 2018 and April 2019, 81 patients underwent reoperations of THA or TKA (58 THAs, 23 TKAs) at our department. Of these 24 were included into the study. Patients were divided into a subgroup with an implant from a cobalt-chromium $(\mathrm{Co}-\mathrm{Cr})$ alloy $(\mathrm{n}=11)$ and subgroup with an implant containing titanium or its alloy $(n=13)$. The subgroup of patients with total joint arthroplasty containing $\mathrm{Ti}$ was reoperated after 13.5 years on average with a range from 0.1 to 22.8 years, whereas the subgroup of patients with total joint arthroplasty without Ti was reoperated after 7.8 years on average with a range of from 2.1 to 23.4 years. Periprosthetic tissues were collected from previously specified collection sites during revision THA ( $\mathrm{n}=16 ; 6$ males and 10 females $)$ and TKA $(\mathrm{n}=8 ; 4$ males and 4 females). Patient characteristics are shown in Table 1. Tissue collection was performed by the same surgeon (JG).

Written informed consent about the use of periprosthetic tissues for the purpose of this study was obtained from each subject prior to inclusion in the study. The Ethics Committee for the Faculty of Medicine and Dentistry, Palacký University Olomouc and the University Hospital Olomouc approved the study in accordance with the Helsinki Declaration (Ministry of Health, VES1631852A).

\section{Sample collection}

Tissue samples of 24 patients were collected immediately after opening of the joint from the internal surface of the pseudocapsule. A superficial layer of pseudosynovial tissue on an area of approximately 1 x $2 \mathrm{~cm}$ was taken for histological examination. A similarly large sample was collected from the vicinity of the previous sample for later determination of concentration of selected metals. The first sample was fixed with $10 \%$ formalin immediately after collection and was subsequently sent for histopathological examination. The second collection was deeply frozen.

\section{Histopathological examination}

The samples were oriented, additionally cut and processed using a standard histological technique with embedding to paraffin blocks after macroscopic assessment at the Institute of Clinical and Molecular Pathology. Two to three representative blocks were selected from each sample after primary hematoxylin - eosin staining and immunohistochemical methods were applied to prepare sections with a thickness of 3 to $4 \mu \mathrm{m}$.

Polyclonal antibodies Polyclonal Rabbit Anti-Human CD117 (DAKO, polyclone, c-kit synonym, tyrosine kinase receptor) and Monoclonal Mouse Anti-Human Mast Cell Tryptase (DAKO, clone AA1), which represents the enzymatic equipment of all human mastocytes, were used for purposes of the immunohistochemical examination.

Monoclonal Mouse Anti-Human CD1a (DAKO, clone 010) and Polyclonal Rabbit Anti-S100 (DAKO, polyclone) antibodies were used for detection of dendritic cells. CD1a are among MHC class I-related superficial glycoproteins, and they indicate immature dendritic and Langerhans cells and cortical lymphocytes with various intensity. S100 protein indicates Langerhans and dendritic cells, but also adipocytes, chondrocytes, melanocytes and glial cells of the neural tissue.

Monoclonal Mouse Anti-Human CD3 (DAKO, clone F7.2.38) antibody was used for detection of T lymphocytes and monoclonal Mouse Anti-Human CD20 (DAKO, clone L26) was used for detection of B lymphocytes. Histiocytes were detected with Mouse Anti-Human CD68 (DAKO, clone PG-M1) antibody.

Immunohistochemistry was performed using an optimised protocol in the Ventana Benchmark XT automated system during final brown staining of the nuclei/ cytoplasm and/or membrane of positive cells.

\section{Histopathological evaluation}

All preparations were evaluated in an optical microscope Olympus BX45 during 20x - 400x magnification (Objective UPLFFLN40X - UIS2, UPlanFLN, 40x/0,75, oo/0,17/FN26.5). Quantification of particular cellular types expressed by a specific antigen was formulated by an absolute count in 20 fields at 400x magnification (HPF). Determination of the membrane type was performed according to the classification of Krenn et al. ${ }^{22}$.

\section{Determination of metals}

The determination of $\mathrm{Co}, \mathrm{Cr}$, Ti and V in tissue samples was carried out by Inductively Coupled Plasma Mass Spectrometry (ICP-MS) after microwave digestion with a mixture of $\mathrm{HNO}_{3}$ and $\mathrm{H}_{2} \mathrm{O}_{2}$. The detailed measurement procedure including sample pretreatment and measures taken to assure quality of results is described in detail in our previous study ${ }^{12}$. 


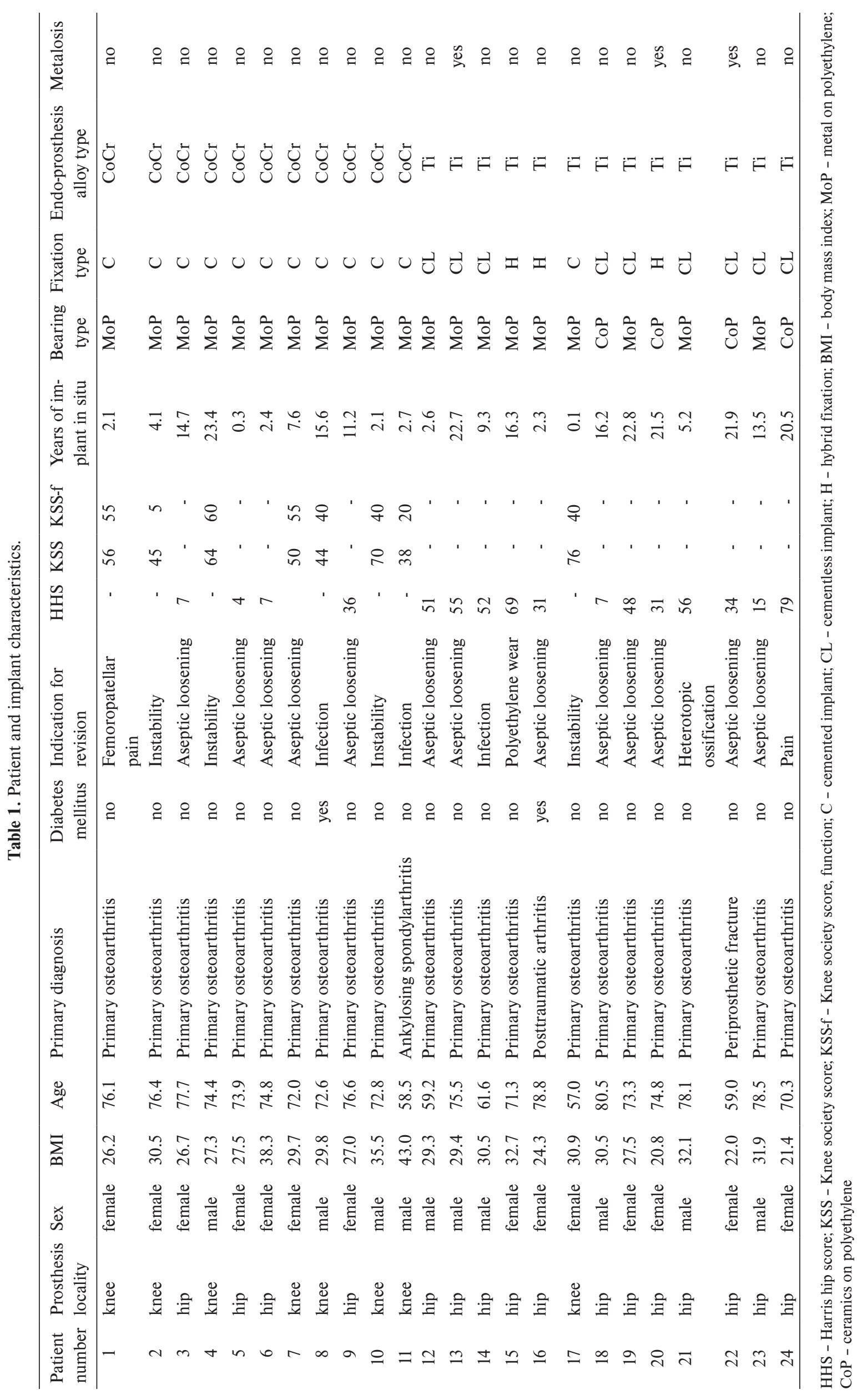




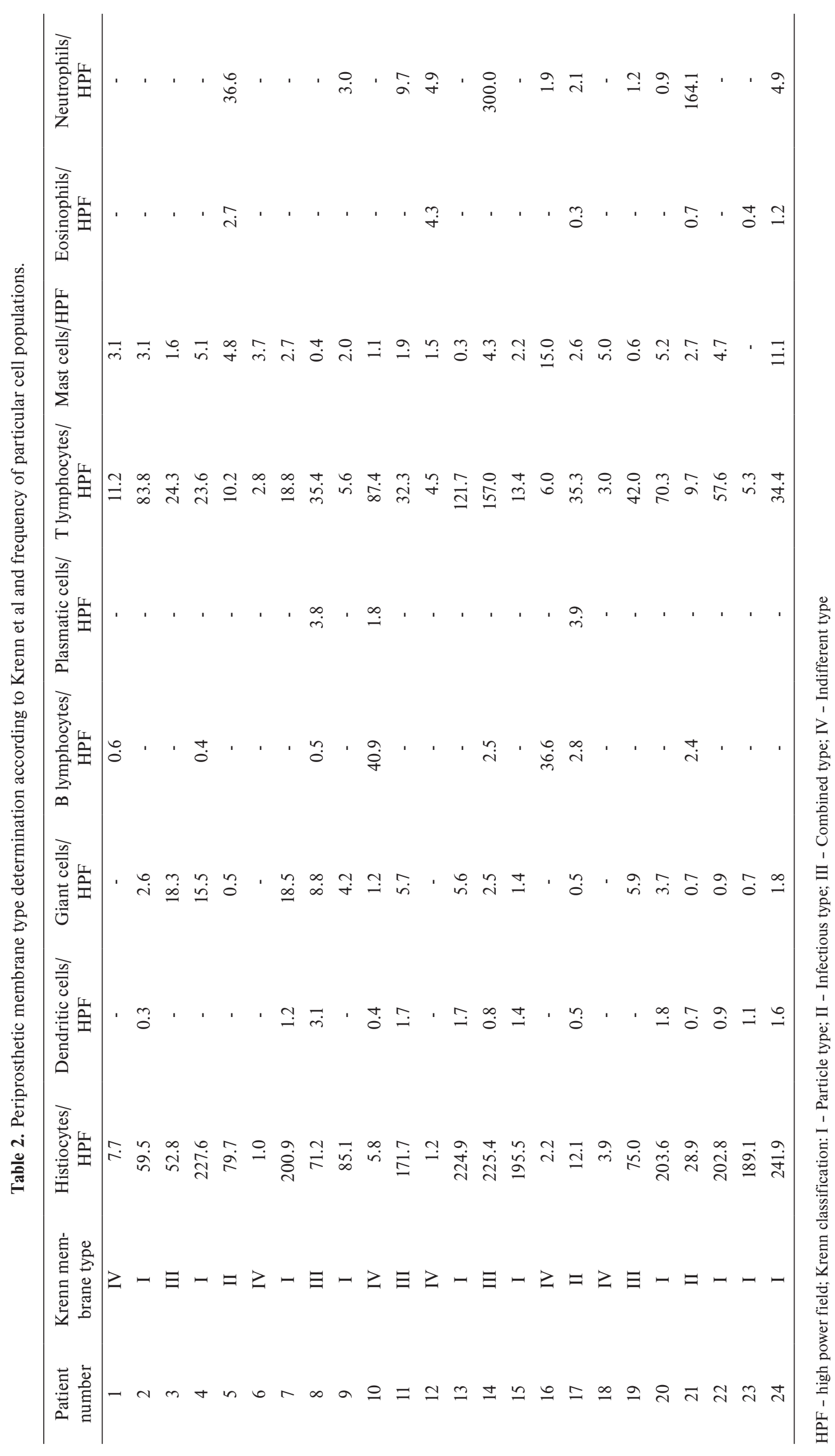



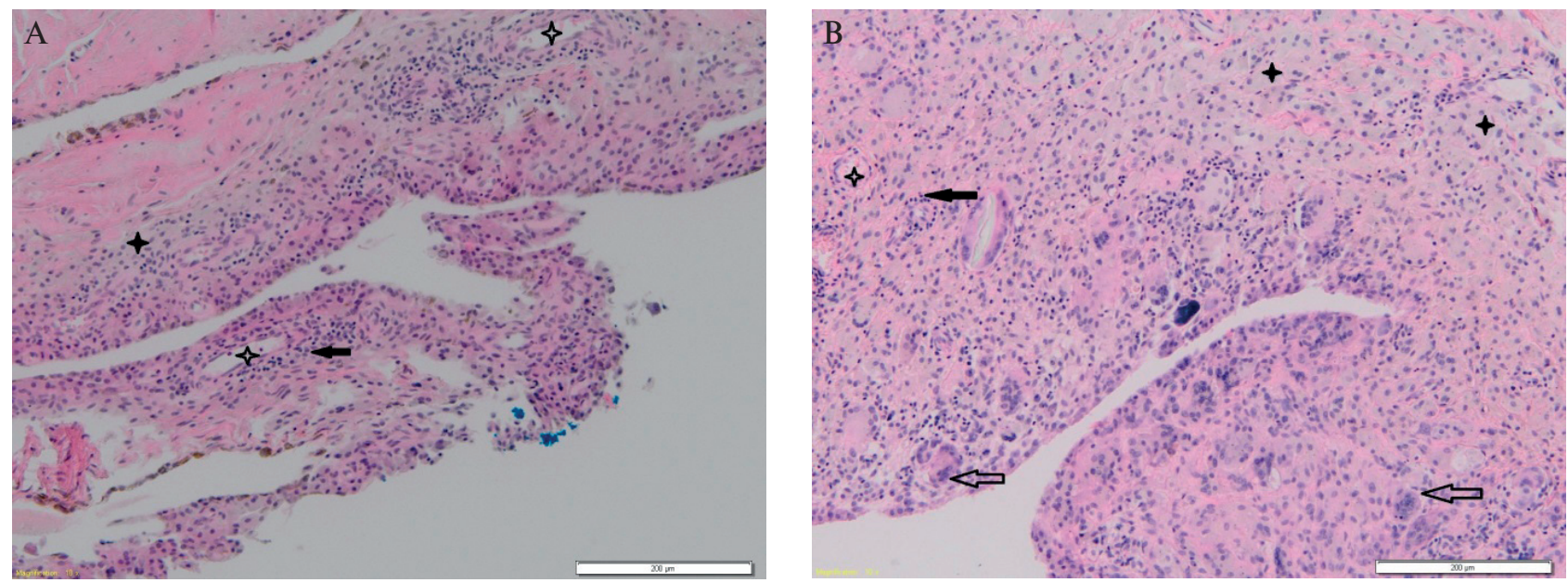

Fig. 1. Pseudosynovial membrane around CoCr implants.

A. Type I membrane according to Krenn and Morawietz - early reaction: Inflammatory infiltration creates a narrow rim of lymphocytes in perivascular localisation with a minimal count of lymphocytes between histiocytes. The figure contains histiocytes and perivascular lymphocytes, giant cells are not present. Wear particles are minimally present, they can be found in superficial areas of the sample. B. Type I membrane according to Krenn and Morawietz - late reaction: Inflammatory infiltration is extensive here, dominated by histiocytes and giant cells. In addition to the perivascular area, lymphocytes are present diffusely among histiocytes. Wear material is abundant in all the parts of the sample.

Pictograms:

+ histiocytes, \& blood vessels, $\leftarrow$ lymphocytes, $\prec$ giant cells, $\triangle$ necrosis
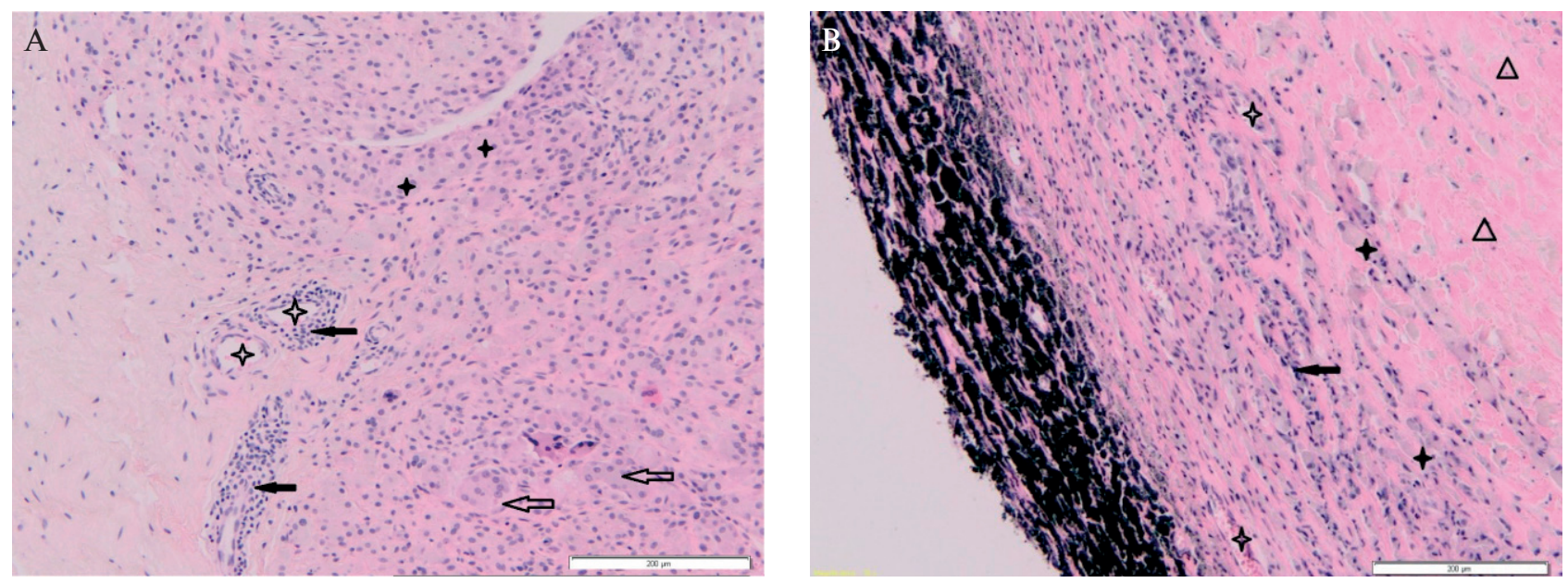

Fig. 2. Pseudosynovial membrane around Ti implants.

A. Type I membrane according to Krenn and Morawietz - early reaction: The inflammatory infiltrate creates a well-defined rim of histiocytes with addition of giant cells and lymphocytes in the perivascular area with sparse lymphocytes between histiocytes. Wear material is less prominent and mostly situated in superficial areas. B. Type I membrane according to Krenn and Morawietz - late reaction: Extensive inflammatory reaction dominated by histiocytes and giant cells. Lymphocytes are more present in deeper parts of the sample comparing to the perivascular area and they become more dispersed among histiocytes. Wear material is richly present in all the parts of the sample. Necrosis is found in the upper right corner.

Pictograms:

+ histiocytes, \& blood vessels, $\leftarrow$ lymphocytes, $\triangleleft$ giant cells, $\triangle$ necrosis

\section{Statistical analysis}

For statistical data treatment, the following software packages were used: NCSS 2007 (NCSS, LLC, USA) where the Mann-Whitney test was evaluated, and QC.Expert 3.2 (Trilobyte Ltd., Czech Republic) where correlation analysis and principal component analy- sis (PCA) were elaborated. Considering that we had a multivariate dataset, an advanced statistical technique (i.e., PCA) was applied to examine the true relationships among our data. 

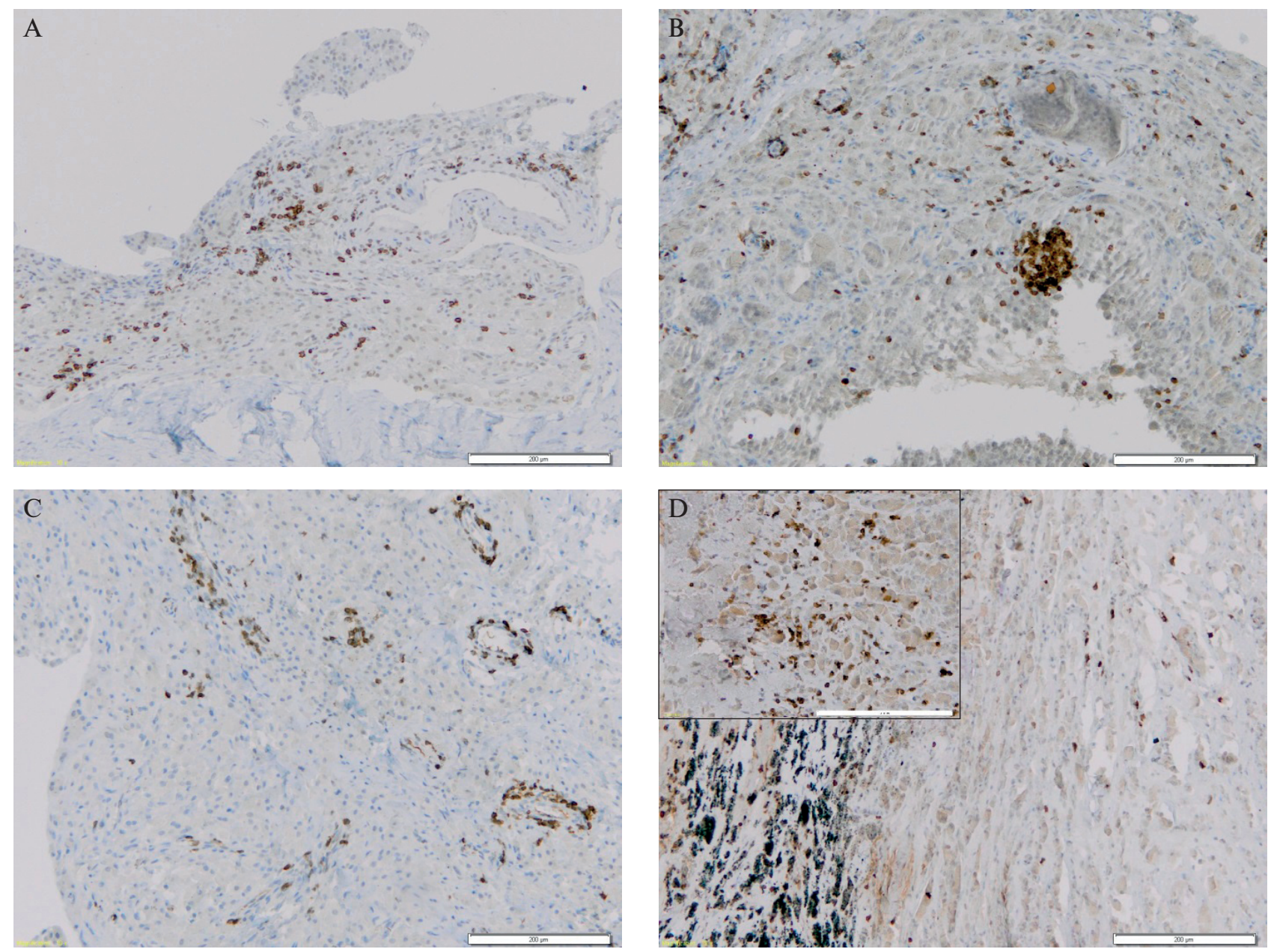

Fig. 3. Immunohistochemical staining of CD3+ T lymphocytes in the membrane.

A. CoCr implant - early revision: Lymphocytes are mainly in the perivascular area; B. CoCr implant - late revision: Lymphocytes are present not only in the perivascular area, in addition they are dispersed among histiocytes. C. Ti implant - early revision: Lymphocytes in the perivascular area with a small amount of lymphocytes between histocytes. D. Ti implant - late revision: The superficial area contains small amount of lymphocytes among histocytes. Inserted figure displays a deeper area, where the lymphocytes are more frequent with a disperse infiltration among histiocytes, conversely, they are less present in the perivascular area.

\section{RESULTS}

\section{Histopathological examination results}

Results of the histological examination, i.e. determination of the membrane type according to Krenn et al..$^{22}$ and frequency of particular cellular populations per $1 \mathrm{HPF}$ are reported in Table 2.

A non-parametric test (Mann-Whitney, $\alpha=0.05$ ) confirmed that there was no statistically significant difference in the levels of histiocytes, dendritic cells, T lymphocytes, mastocytes, neutrophils or membrane type between both the basic subgroups. Thus, no differences were confirmed among the observed histological parameters and reported subgroups, which leads to a conclusion that the analysis of clear histological parameters does not reveal significant differences between the subgroups of patients with the titanium and non-titanium implants. Other histological parameters were not subject to the statistical test due to predominance of zero levels.
However, the morphological image of both the groups is changing with the duration of implantation. The extent and intensity of inflammatory infiltration was lower in both the groups during a short period from implantation and gradually increased with a growing period from implantation (Fig. 1 and 2). Necrosis occurs more frequently together with an increasing extent of the inflammatory response. Histiocytes form narrow rims below the synovial cover at first, then with the extending interval from implantation they form lamellar to nodular infiltrations. The number of giant cells rises as well as the content of foreign material, which shows its highest volume in the area of contact with the implant. The number of lymphocytes and their distribution also change in time (Fig. 3). Infiltrations are only perivascular and in the vicinity of the surface at first. With a growing period from implantation, higher migration of lymphocytes is seen from perivascular localisations to the areas of inflammatory infiltration. These changes are more expressed in the group with $\mathrm{Ti}$ total joint arthroplasty (Fig. 3C and D). 


\section{Determination of the metal levels in periprosthetic tissues}

Results of a sample analysis for the presence of metals ( $\mathrm{Ti}, \mathrm{V}, \mathrm{Co}$ and $\mathrm{Cr}$ ) in the layer most adjacent to total joint arthroplasty are reported in Table 3 . With statistical testing of consistency we evaluated the differences among the levels of metals in patients, who had total joint arthroplasty in the evaluated joint from a titanium alloy, and in patients with total joint arthroplasty with no Ti. The non-parametric Mann-Whitney test confirmed the differences in $\mathrm{Ti}, \mathrm{Co}, \mathrm{Cr}$ and $\mathrm{V}$ (per $\alpha=0.05$ ). Difference in the levels of titanium explains why we performed dividing into two groups, separately for the following correlation and PCA analysis.

\section{Correlation analyses}

For evaluation of relations among particular metals (groups of metals) and histological findings, or for evaluation of relation between the time between primary and revision surgery ("length of exposure"; LoE) and concentrations of metals, we used a correlation analysis using the Pearson correlation coefficient and testing of its statistical significance $(\alpha=0.05)$.
Testing within the group with implants without Ti

Statistically significant correlation (for $\alpha=0.05$ ) between the length of exposure and $\mathrm{Cr}$ level $(\mathrm{r}=0.727)$ and further between the Co and $\mathrm{Cr}$ levels $(\mathrm{r}=0.772)$ was demonstrated. Correlation between $\mathrm{Co}$ and $\mathrm{Cr}$ is easily explainable, since both the metals can be found in total joint arthroplasty. Correlation between the $\mathrm{LoE}$ and $\mathrm{Cr}$ level is also easily explainable - the longer the implant is in the body, the more metal is released to the surrounding tissue. Co-Cr implants have a small layer of $\mathrm{Cr}_{2} \mathrm{O}_{3}$ on their surface, therefore correlation between LoE and Cr level, not the Co level, was confirmed.

\section{Testing within the group with Ti implants:}

Statistically significant correlations (for $\alpha=0.05$ ) between the LoE and Ti concentration $(r=0.577)$, LoE and $\mathrm{V}$ concentration $(\mathrm{r}=0.560)$ and for $\mathrm{Ti}$ and $\mathrm{V}(\mathrm{r}=$ 0.714 ), respectively, were demonstrated. Both metals can be found in titanium total joint arthroplasties and it is a fact - as in total joint arthroplasties from a CoCrMo alloy - that $\mathrm{Ti}$ and $\mathrm{V}$ concentrations in the surrounding periprosthetic tissue are growing with the LoE.

Table 3. Metal concentrations in periprosthetic tissues.

\begin{tabular}{|c|c|c|c|c|c|c|}
\hline Patient number & $\begin{array}{c}\text { Endoprosthesis } \\
\text { alloy type }\end{array}$ & $\begin{array}{l}\text { Years of implant } \\
\text { in situ }\end{array}$ & $\begin{array}{c}\mathrm{Ti} \\
(\mathrm{mg} / \mathrm{kg})\end{array}$ & $\begin{array}{c}\mathrm{V} \\
(\mathrm{mg} / \mathrm{kg})\end{array}$ & $\begin{array}{c}\mathrm{Cr} \\
(\mathrm{mg} / \mathrm{kg})\end{array}$ & $\begin{array}{c}\mathrm{Co} \\
(\mathrm{mg} / \mathrm{kg})\end{array}$ \\
\hline 1 & $\mathrm{CoCr}$ & 2.1 & 0.35 & 0.02 & 24.59 & 6.50 \\
\hline 2 & $\mathrm{CoCr}$ & 4.1 & 0.69 & 0.04 & 7.72 & 0.03 \\
\hline 3 & $\mathrm{CoCr}$ & 14.7 & 0.53 & 0.01 & 3.46 & 0.83 \\
\hline 4 & $\mathrm{CoCr}$ & 23.4 & 6.07 & 0.31 & 386.48 & 24.99 \\
\hline 5 & $\mathrm{CoCr}$ & 0.3 & 2.26 & 0.04 & 4.45 & 1.19 \\
\hline 6 & $\mathrm{CoCr}$ & 2.4 & 2.83 & 0.01 & 0.56 & 0.02 \\
\hline 7 & $\mathrm{CoCr}$ & 7.6 & 2.20 & 0.01 & 6.67 & 6.60 \\
\hline 8 & $\mathrm{CoCr}$ & 15.6 & 20.24 & 0.85 & 24.48 & 34.14 \\
\hline 9 & $\mathrm{CoCr}$ & 11.2 & 2.69 & 0.01 & 9.53 & 14.50 \\
\hline 10 & $\mathrm{CoCr}$ & 2.1 & 0.37 & 0.03 & 7.06 & 0.06 \\
\hline 11 & $\mathrm{CoCr}$ & 2.7 & 30.81 & 1.28 & 6.77 & 0.92 \\
\hline 12 & $\mathrm{Ti}$ & 2.6 & 34.88 & 0.64 & 4.69 & 3.09 \\
\hline 13 & $\mathrm{Ti}$ & 22.7 & 3492.69 & 215.89 & 37.40 & 43.23 \\
\hline 14 & $\mathrm{Ti}$ & 9.3 & 8.94 & 0.04 & 169.19 & 279.57 \\
\hline 15 & $\mathrm{Ti}$ & 16.3 & 8.14 & 0.05 & 24.81 & 8.37 \\
\hline 16 & $\mathrm{Ti}$ & 2.3 & 2.22 & 0.02 & 1.86 & 0.03 \\
\hline 17 & $\mathrm{Ti}$ & 0.1 & 2.27 & 0.04 & 7.29 & 5.79 \\
\hline 18 & $\mathrm{Ti}$ & 16.2 & 29.42 & 0.02 & 0.80 & 0.02 \\
\hline 19 & $\mathrm{Ti}$ & 22.8 & 11.38 & 0.25 & 5.72 & 8.54 \\
\hline 20 & $\mathrm{Ti}$ & 21.5 & 87.11 & 0.16 & 162.29 & 18.37 \\
\hline 21 & $\mathrm{Ti}$ & 5.2 & 5.11 & 0.01 & 4.59 & 6.73 \\
\hline 22 & $\mathrm{Ti}$ & 21.9 & 239.09 & 11.30 & 2.76 & 0.09 \\
\hline 23 & $\mathrm{Ti}$ & 13.5 & 17.99 & 0.08 & 39.65 & 68.66 \\
\hline 24 & $\mathrm{Ti}$ & 20.5 & 12.95 & 0.01 & 0.59 & 0.03 \\
\hline
\end{tabular}




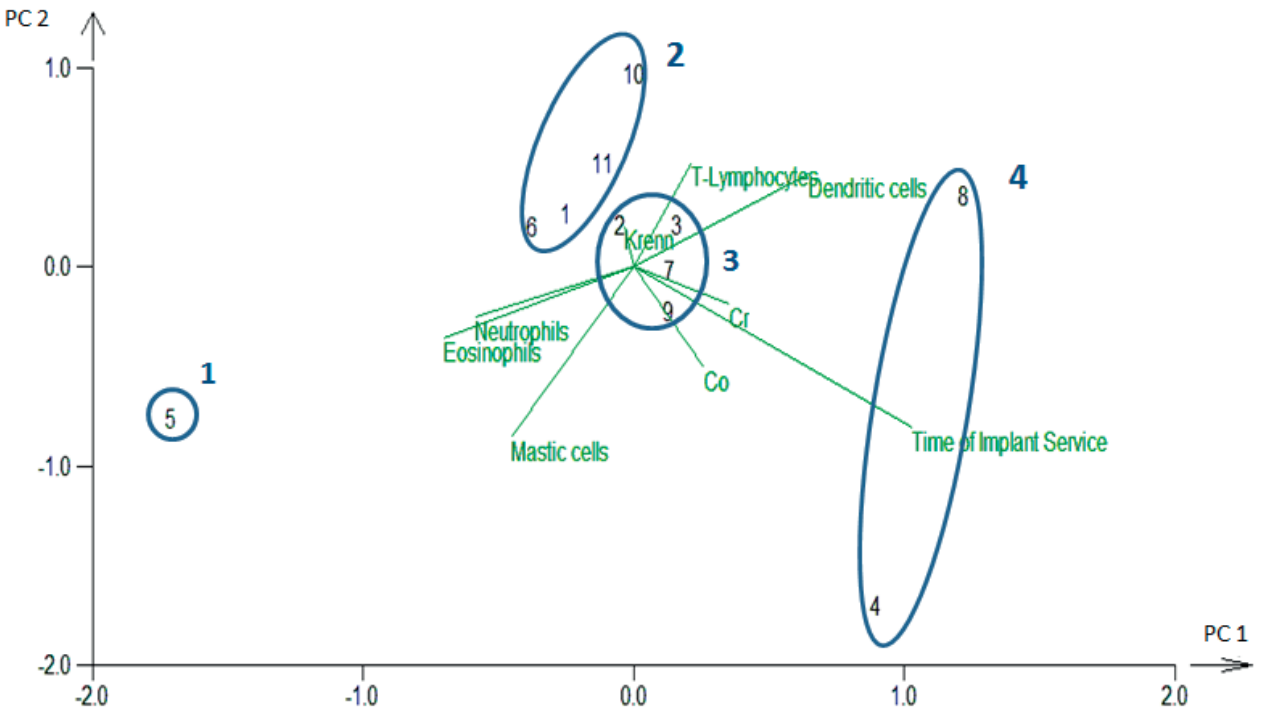

Fig. 4. PCA analysis biplot for the CoCr implant group $(n=11)$. The first and second principal components explain $61.9 \%$ of variability presented in the data. The largest influence is given by the length of exposition, which can be identified as the main component (x axis); PCA - Principal Component Analysis; n - number.

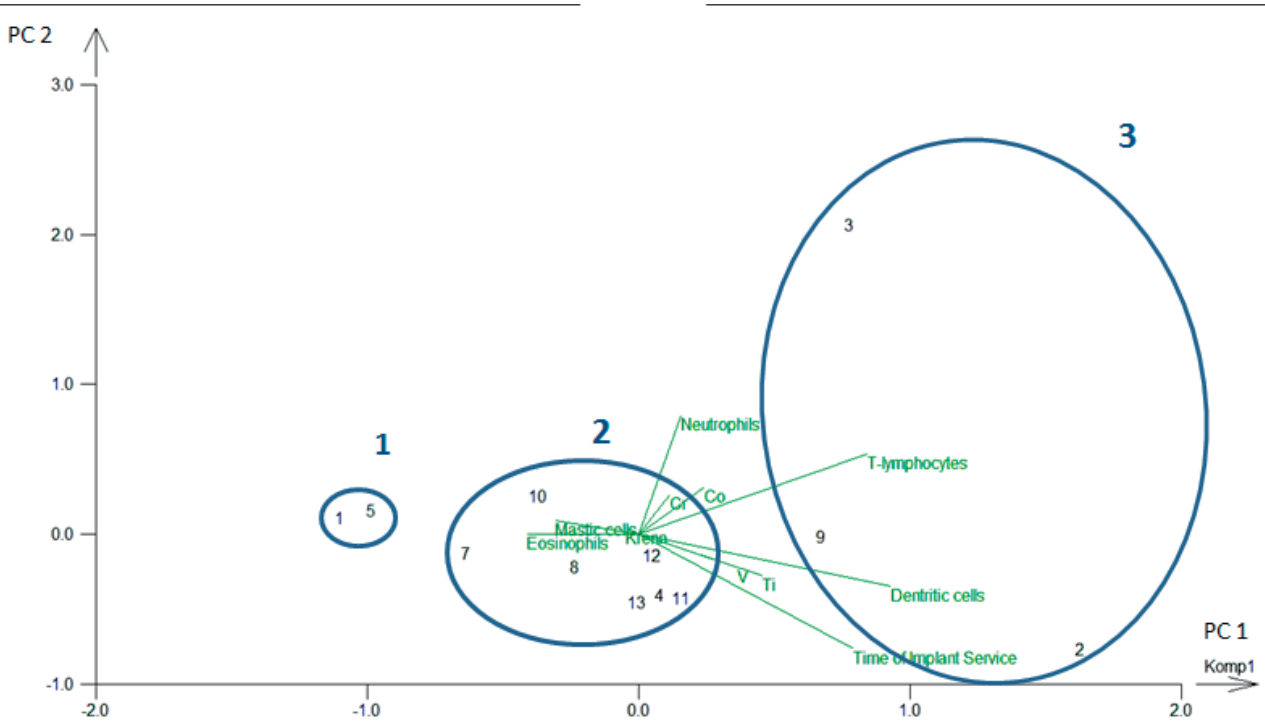

Fig. 5. PCA analysis biplot for the Ti implant group $(n=12)$. The first and second principal components explain $61.1 \%$ of variability presented in the data. The largest influence is given by the length of exposition, which can be identified as the main component ( $\mathrm{x}$ axis); PCA - Principal Component Analysis; $\mathrm{n}$ - number.

\section{Principle component analysis}

We mapped each group separately with regard to a small number of subjects and variability in the findings between the titanium $(n=12$; one patient with a very short period of implant survival of 0.1 year was excluded from the PCA analysis, since he did not fall to any cluster; "there was no time for metals to be released into the surrounding area") and cobalt-chromium ( $\mathrm{n}=11$ patients) implants. The following variables were included to the PCA: LoE, dendritic cells, T lymphocytes, mastocytes, eosinophils, neutrophils, membrane type and particular metals. We identified several subgroups (cluster) in both the groups in dependence on the LoE.

\section{PCA analysis for the group with implants without Ti}

(Co and Cr included in the PCA from metals):

PCA could determine several clusters, which differed in the LoE, type of the membrane and presence of immune cells. Results are shown in Fig. 4 and tell us: i) short LoE, type IV membrane and higher presence of neutrophils were determining for the first aggregation; ii) moderate $\operatorname{LoE}$ (2.1-2.7 years) was determining for the 
second cluster; membrane type was not determining, as well as any of evaluated cellular populations; iii) the longest LoE ( 5 and more years), high Co-Cr concentrations were determining for the third cluster, membrane type was not determining, T lymphocytes were predominant among cells.

\section{Group with titanium implants}

\section{(Ti, Vincluded in the PCA from metals):}

Also in this group the PCA could determine several clusters, which differed in the LoE, type of the membrane and presence of immune cells. Results are shown in Fig. 5: i) short exposure, type IV membrane, low levels of metals and zero dendritic cells were determining for the first cluster; ii) moderate to longer exposure and lower levels of metals were determining for the second cluster; on the contrary, no membrane type, not even any of evaluated cellular populations were determining; iii) long period of exposure, high levels of released metals in the tissues and high $\mathrm{T}$ lymphocyte levels were determining for the third cluster.

\section{DISCUSSION}

In this paper we evaluated the histological type of the periprosthetic membrane including representation of immune cells in relation to tissue concentrations of metals released from the MoP or CoP total joint arthroplasty. We found out that time that elapsed from the index surgery (LoE) is the main determining factor. With its growing length, the concentrations of metals originating from the implant increase. Growing $\mathrm{T}$ lymphocyte frequency or changing type of their distribution corresponded to high concentrations of metals in the tissues and can be therefore associated with late failure. On the contrary, the membrane type according to Krenn was not determining from the perspective of detected metal concentrations.

It has been previously demonstrated that joint arthroplasties from metallic alloys are not inert, and the surrounding tissues response to released metallic particles and ions by an inflammatory reaction ${ }^{23}$. This response may result in failure of $\mathrm{MoM}$ implants ${ }^{24}$ and it probably even contributes to failure of MoP implants ${ }^{25}$. According to our best knowledge a relation between the concentration of metals in periprosthetic tissues and the type of tissue response in the MoP and CoP total joint arthroplasty has not yet been published in the literature. Relations of the histological finding with tissue metals have been reported in more details in MoM THA, where multivalent results have been published - on one hand, an unspecified immune response with plenty of macrophages in correlation with high tissue concentration of metals and lymphocytic infiltration in the tissues associated with low concentration of metals were demonstrated ${ }^{26}$. On the other hand, Lohmann found an opposite relation, thus low concentrations of metals with macrophage infiltration and high tissue concentrations of metals associated with lymphocytic infiltration, which is more consistent with our results ${ }^{15}$. No clear correlation in dependence on concentration of metals has been found in a recent study comparing the histopathological finding in relation to concentrations of metals in MoM total joint arthroplasties and resurfacing ${ }^{27}$. Growing concentration of metals released in periprosthetic tissues with increasing length of implant service has been found in both the groups of our patients, which is in agreement with our previous work ${ }^{12}$. We did not measure the serum levels of metals, since no correlation between the tissue and serum levels, not even their significance for failure of total joint arthroplasty were demonstrated ${ }^{12,15}$. Increased levels of $\mathrm{Cr}$ and Co were found in some of the samples from the Ti group, this is given by the use of a CoCr head. Fretting corrosion at the trunnion may be the source of these metals here ${ }^{28}$. On the contrary, low levels of $\mathrm{V}$ (and as well $\mathrm{Nb}$ - unpublished data) in this group are given by their low percentage representation in the alloy.

Tissue response to the presence of the implant and its particles is gradually becoming unanimous after longer exposition and takes a quite uniform character. Except for the period of membrane formation and maturation, when higher neutrophil concentration was present, the membrane type according to Krenn ${ }^{22}$ did not determine its host into one of the studied groups according to metal type and tissue metal contents respectively. There are at least two possible explanations. The first one is related to an unspecific response to the presence of prosthetic particles, from which only a part is formed by metals. The second explanation could be associated with relative insensitivity of the classification according to Krenn to the presence of different types of particles (their concentrations) in the tissues. This classification was originally designed for differentiation of basic peri-implant pathologies $^{29}$. In its reviewed version ${ }^{22}$, it even contains an algorithm for assessment of particles (according to material, size and quantity), which should induce tissue changes. However, based on it, the response to abrasion should include the abrasion-induced type of membrane, membrane of the combined type, and also membrane of the fibrous type $^{22}$. Since there is a certain discrepancy in this area and not even our study could differentiate tissue changes more finely in dependence on concentrations of metals, replication studies should be performed at different sites by experienced pathologists.

Metal debris is not considered as the main initiator of the inflammatory tissue response to prosthetic presence, but there is a stronger pathophysiologic connection to $\mathrm{T}$ lymphocytes when compared with the reaction to polyethylene particles as a foreign body. A non-specific foreign body reaction primarily includes macrophages, giant cells, fibroblasts and occasional lymphocytes and small calibre blood vessels, whereas in type IV reaction a main role is played by $\mathrm{T}$ lymphocytes in sustaining the chronic inflammatory reaction ${ }^{30}$. Higher frequency of $\mathrm{T}$ lymphocytes was present in our study in the tissues around titanium and also non-titanium non-MoM THAs and TKAs. A high number of T lymphocytes in periprosthetic tissues rising with time point out to an increasing 
contribution of specific immune response (delayed-type IV reactions) (ref. ${ }^{31,32}$ ) as well as the development of tolerance $^{33}$, apparently in dependence on increasing concentration of metals.

Importantly, the activation of $\mathrm{T}$ lymphocytes during an immune response triggers a series of events/pathways leading together to a reaction to stimuli. However, their role is strictly integrated to a particular situation in the tissue they work in ${ }^{34}$. In later revisions (i.e. with longer LoE) we observed both a higher count of $\mathrm{T}$ lymphocytes and change of their distribution in the area of inflammation. Higher accumulation of lymphocytes was already previously reported in the tissues around MoM THA (ref. ${ }^{35}$ ), where the levels of metals are significantly much higher than in case of MoP or CoP bearing pairs. In fact, higher frequency of $\mathrm{T}$ lymphocytes is not only a domain of MoM pairs, it was also observed in the tissues around MoP total joint arthroplasties ${ }^{36,37}$. Modular connections, where fretting corrosion develops, are the main source of metallic particles and ions in non-MoM total joint arthroplasties $^{7,38}$. A higher presence of CD4+ T lymphocytes was seen in dual modular neck hip prostheses ${ }^{39}$. Despite the fact that the way how metallic particles and ions stimulate the immune apparatus of the host was described ${ }^{23,40,41}$, it is not clear if this is a way common for all metals and what is the threshold amount of metals, which may induce this "specific" response. The gap in our understanding of biotribocorrosion may be filled in the future for example by new tests allowing simultaneous assessment of tribocorrosion in the presence of cells and tissues ${ }^{42}$.

Our study is limited by a low number of cases from two different localities and heterogeneous metal composition of implants, which is further decreasing the provided sample size for each group. On the other hand, a variety of environments for adverse reaction to metals has been a subject of the study. We collected the samples in a standard way, but in a relatively low volume of the periprosthetic tissue, therefore, we cannot rule out that we would come to different findings at another collecting site. We studied this option in the previous paper and we drew a conclusion that variability in the tissue response in one host is relatively low ${ }^{43}$. A certain bias may have developed even by the fact that the implants from the Ti group had $\mathrm{CoCr}$ heads, which resulted in "admixture" of these metals in the final analysed material. On the contrary, it is less probable that concentrations of metals in a membrane tightly adjacent to the implant could affect serum concentrations of metals from other anatomical areas, particularly if we take into account the fact that in the previous study we demonstrated minimal serum concentrations of metals in those, who had MoP, CoP, or CoC joint pairs, and no association between serum and tissue concentration $^{12}$. During the tissue analysis, we were unable to control the effect of the following variables in the tissue reaction: i) chronic mechanic stresses (including hydromechanics of fluids), developing during each step; ii) ageing of the periprosthetic tissues and implant-bone connections; and iii) polyethylene debris. This provides opportunity for future research, where a reaction to PE debris is directly compared to reaction to metals given as a function of their respective concentration, ideally including a cytokine profile study in the same localities.

\section{CONCLUSIONS}

Current research shows that the use of TKA and THA is associated with continual release of polyethylene particles and even metals, which significantly contributes to the periprosthetic tissue reaction. We also start to understand more exactly the relation between the immune apparatus and prosthetic particles, which stimulate the sensors of innate and adaptive immunity. As a result, pathological debris-induced inflammation subsequently develops in some patients. This paper confirms the ability of tissues to accumulate released metals from THA and TKA and change their character in relation to the length of exposure regardless of whether the implant is of cobaltchromium or titanium alloy. $\mathrm{T}$ lymphocytes play a special role; their incidence grows in relation to concentration of metals and length of the implant in situ regardless of material composition of total joint arthroplasty. In contrast, variability in concentration of metals is apparently not reflected in frequency of other types of immune cells (histiocytes, dendritic cells, mastocytes, eosinophils and neutrophils). Classification of periprosthetic membranes cannot predict concentrations of metals in these tissues.

\section{Ethics approval and consent to participate}

The local Ethics Committee approved this study in accordance with the Helsinki Declaration; all the enrolled patients agreed with the use of anonymized data for the research purpose of this study.

Acknowledgement: The study was supported from the resources of the Ministry of Health of the Czech Republic - Development of a Research Organization (University Hospital Olomouc, 00098892) and the grant no. NV1631852A.

Conflict of interest statement: The authors declare that they have no competing interests regarding publication of this article.

Author contributions: $\mathrm{MH}$, collection of clinical data, tissue sampling, data analysis, writing; DM, determination of metal contents in clinical materials, statistics and information analysis, writing; ZS, histopathological analysis, writing; JG, conceptualization, study design, data interpretation; writing, editing. All the authors read and approved the final manuscript.

\section{REFERENCES}

1. Stepanovska J, Matejka R, Rosina J, Bacakova L, Kolarova H. Treatments for enhancing the biocompatibility of titanium implants. Biomedical papers of the Medical Faculty of the University Palacky, Olomouc, Czechoslovakia 2020;164(1):23-33. doi: 10.5507/ bp.2019.062

2. Evans JT, Evans JP, Walker RW, Blom AW, Whitehouse MR, Sayers A. How long does a hip replacement last? A systematic review and 
meta-analysis of case series and national registry reports with more than 15 years of follow-up. Lancet 2019;393:647-54. doi: 10.1016/ S0140-6736(18)31665-9

3. Evans JT, Walker RW, Evans JP, Blom AW, Sayers A, Whitehouse MR How long does a knee replacement last? A systematic review and meta-analysis of case series and national registry reports with more than 15 years of follow-up. Lancet 2019;393:655-63. doi: 10.1016/ S0140-6736(18)32531-5

4. Chang JS, Haddad FS. Long-term survivorship of hip and knee arthroplasty. The bone \& joint journal 2020;102-B:401-2. doi: 10.1302/0301-620X.102B4.BJJ-2020-0183

5. Dyskova T, Kriegova E, Slobodova Z, Zehnalova S, Kudelka M, Schneiderova P, Fillerova R, Gallo J. Inflammation time-axis in aseptic loosening of total knee arthroplasty: A preliminary study. PLoS One 2019;14:e0221056. doi: 10.1371/journal.pone.0221056

6. Pajarinen J, Gallo J, Takagi M, Goodman SB, Mjoberg B. Particle disease really does exist. Acta Orthop 2018;89:133-6. doi: 10.1080/17453674.2017.1402463

7. Urish KL, Giori NJ, Lemons JE, Mihalko WM, Hallab N. Trunnion Corrosion in Total Hip Arthroplasty-Basic Concepts. Orthop Clin North Am 2019;50:281-8. doi: 10.1016/j.ocl.2019.02.001

8. Goodman SB, Gallo J, Gibon E, Takagi M. Diagnosis and management of implant debris-associated inflammation. Expert Rev Med Devices 2019:1-16. doi: 10.1080/17434440.2020.1702024

9. Laaksonen I, Galea VP, Connelly JW, Matuszak SJ, Marega L, Madanat R, Muratoglu O, Malchau H. Progression of adverse local tissue reaction in ASR metal-on-metal hip arthroplasty: a longitudinal MARS-MRI study at mid- to long-term. Hip Int 2019 Dec 23:1120700019894668. doi: 10.1177/1120700019894668 [Epub ahead of print]

10. Dundon JM, Ramkumar PN, Lajam C. Tribocorrosion in Total Hip Arthroplasty. JBJS Rev 2017;5(3). pii: 01874474-201703000-00002. doi: 10.2106/JBJS.RVW.16.00055

11. Diomidis N, Mischler S, More NS, Roy M. Tribo-electrochemical characterization of metallic biomaterials for total joint replacement. Acta Biomater 2012;8:852-9. doi: 10.1016/j.actbio.2011.09.034

12. Kuba M, Gallo J, Pluhacek T, Hobza M, Milde D. Content of distinct metals in periprosthetic tissues and pseudosynovial joint fluid in patients with total joint arthroplasty. J Biomed Mater Res B Appl Biomater 2019;107:454-62. doi: 10.1002/jbm.b.34137

13. Lehtovirta L, Reito A, Lainiala O, Parkkinen J, Hothi H, Henckel J Hart A, Eskelinen A. Host-specific factors affect the pathogenesis of adverse reaction to metal debris. BMC musculoskeletal disorders 2019;20:195. doi: 10.1186/s12891-019-2578-0

14. Lehtovirta L, Reito A, Parkkinen J, Peraniemi S, Vepsalainen J, Eskelinen A. Association between periprosthetic tissue metal content, whole blood and synovial fluid metal ion levels and histopathological findings in patients with failed metal-on-metal hip replacement. PloS One 2018;13:e0197614. doi: 10.1371/journal. pone.0197614

15. Lohmann $\mathrm{CH}$, Meyer $\mathrm{H}$, Nuechtern JV, Singh $\mathrm{G}$, Junk-Jantsch $\mathrm{S}$ Schmotzer H, Morlock MM, Pfluger G. Periprosthetic tissue metal content but not serum metal content predicts the type of tissue response in failed small-diameter metal-on-metal total hip arthroplasties. J Bone Joint Surg Am 2013;95:1561-8. doi: 10.2106/JBJS.L.01273

16. Salib CG, Lewallen EA, Paradise CR, Tibbo ME, Robin JX, Trousdale WH, Morrey LM, Xiao J, Turner TW, Limberg AK, Jay AG, Thaler R, Dudakovic A, Sanchez-Sotelo J, Morrey ME, Berry DJ, Lewallen DG, van Wijnen AJ, Abdel MP. Molecular pathology of adverse local tissue reaction caused by metal-on-metal implants defined by RNA-seq Genomics 2019;111:1404-11. doi: 10.1016/j.ygeno.2018.09.013

17. Campbell PA, Kung MS, Hsu AR, Jacobs JJ. Do retrieval analysis and blood metal measurements contribute to our understanding of adverse local tissue reactions? Clin Orthop Relat Res 2014;472:3718-27. doi:10.1007/s11999-014-3893-2

18. Ricciardi BF, Nocon AA, Jerabek SA, Wilner G, Kaplowitz E, Goldring $S R$, Purdue PE, Perino G. Histopathological characterization of corrosion product associated adverse local tissue reaction in hip implants: a study of 285 cases. BMC Clin Pathol 2016;16:3. doi: 10.1186/ s12907-016-0025-9

19. Davies AP, Willert HG, Campbell PA, Learmonth ID, Case CP. An unusual lymphocytic perivascular infiltration in tissues around con- temporary metal-on-metal joint replacements. J Bone Joint Surg Am 2005:87:18-27. doi: 10.2106/JBJS.C.00949

20. Lohmann $\mathrm{CH}$, Singh $\mathrm{G}$, Willert HG, Buchhorn $\mathrm{GH}$. Metallic debris from metal-on-metal total hip arthroplasty regulates periprosthetic tissues. World J Orthop 2014;5:660-6. doi: 10.5312/wjo.v5.i5.660

21. Samelko L, Caicedo MS, Jacobs J and Hallab NJ. Transition from metal-DTH resistance to susceptibility is facilitated by NLRP3 inflammasome signaling induced Th17 reactivity: Implications for orthopedic implants. PLoS One 2019;14:e0210336. doi: 10.1371/ journal.pone.0210336

22. Krenn V, Morawietz L, Perino G, Kienapfel H, Ascherl R, Hassenpflug GJ, Thomsen $M$, Thomas $P$, Huber M, Kendoff D, Baumhoer D, Krukemeyer MG, Natu S, Boettner F, Zustin J, Kolbel B, Ruther W, Kretzer JP, Tiemann A, Trampuz A, Frommelt L, Tichilow R, Soder S, Muller S, Parvizi J, Illgner U, Gehrke T. Revised histopathological consensus classification of joint implant related pathology. Pathol Res Pract 2014;210:779-86. doi: 10.1016/j.prp.2014.09.017

23. Hallab NJ, Jacobs JJ. Biologic effects of implant debris. Bulletin of the NYU hospital for joint diseases 2009;67:182-8.

24. Reito A, Lainiala O, Elo P, Eskelinen A. Prevalence of Failure due to Adverse Reaction to Metal Debris in Modern, Medium and Large Diameter Metal-on-Metal Hip Replacements--The Effect of Novel Screening Methods: Systematic Review and Metaregression Analysis. PLoS One 2016;11:e0147872. doi: 10.1371/journal.pone.0147872

25. Whitehouse MR, Endo M, Zachara S, Nielsen TO, Greidanus NV Masri BA, Garbuz DS, Duncan CP. Adverse local tissue reactions in metal-on-polyethylene total hip arthroplasty due to trunnion corrosion: the risk of misdiagnosis. Bone Joint J 2015;97-b:1024-30. doi: 10.1302/0301-620x.97b8.34682

26. Campbell P, Ebramzadeh E, Nelson S, Takamura K, De Smet $K$ Amstutz HC. Histological features of pseudotumor-like tissues from metal-on-metal hips. Clin Orthop Relat Res 2010;468:2321-7. doi: 10.1007/s11999-010-1372-y

27. Lehtovirta L, Reito A, Parkkinen J, Peräniemi S, Vepsäläinen J, Eskelinen A. Association between periprosthetic tissue metal content, whole blood and synovial fluid metal ion levels and histopathological findings in patients with failed metal-on-metal hip replacement. PloS one 2018;13:e0197614-e0197614. doi: 10.1371/ journal.pone.0197614

28. Sultan AA, Cantrell WA, Khlopas A, Berger RJ, Sodhi N, Molloy RM, Krebs VE and Mont MA. Evidence-Based Management of Trunnionosis in Metal-on-Polyethylene Total Hip Arthroplasty: A Systematic Review. J Arthroplasty 2018;33:3343-53. doi: 10.1016/j. arth.2018.05.035

29. Morawietz L, Classen RA, Schroder JH, Dynybil C, Perka C, Skwara A Neidel J, Gehrke T, Frommelt L, Hansen T, Otto M, Barden B, Aigner T, Stiehl P, Schubert T, Meyer-Scholten C, Konig A, Strobel P, Rader CP, Kirschner S, Lintner F, Ruther W, Bos I, Hendrich C, Kriegsmann J, Krenn V. Proposal for a histopathological consensus classification of the periprosthetic interface membrane. J Clin Pathol 2006;59:591-7. doi: $10.1136 / j$ cp. 2005.027458

30. Goodman SB. Wear particles, periprosthetic osteolysis and the immune system. Biomaterials 2007;28:5044-8. doi: 10.1016/j.biomaterials.2007.06.035

31. Lohmann $\mathrm{CH}$, Hameister R, Singh G. Allergies in orthopaedic and trauma surgery. Orthop Traumatol Surg Res 2017;103:S75-S81. doi: 10.1016/j.otsr.2016.06.021

32. Roberts TT, Haines CM, UhI RL. Allergic or Hypersensitivity Reactions to Orthopaedic Implants. J Am Acad Orthop Surg 2017;25:693-702. doi: 10.5435/JAAOS-D-16-00007

33. McCarville JL, Ayres JS. Disease tolerance: concept and mechanisms. Curr Opin Immunol 2018;50:88-93. doi: 10.1016/j.coi.2017.12.003

34. Peterson EJ, Maltzman JS. T-cell activation and tolerance. In: Rich RR (ed) Clinical immunology: Principles and practice. Elsevier, 2019, pp.183-196.

35. Hopf F, Thomas P, Sesselmann S, Thomsen MN, Hopf M, Hopf J, Krukemeyer MG, Resch H, Krenn V. CD3+ lymphocytosis in the peri-implant membrane of 222 loosened joint endoprostheses depends on the tribological pairing. Acta Orthop 2017;88:642-8. doi: 10.1080/17453674.2017.1362774

36. von Domarus C, Rosenberg JP, Ruther W, Zustin J. Necrobiosis and T-lymphocyte infiltration in retrieved aseptically loosened metalon-polyethylene arthroplasties. Acta Orthop 2011;82:596-601. doi: 10.3109/17453674.2011.625534 
37. Ng VY, Lombardi AV, Jr., Berend KR, Skeels MD, Adams JB. Perivascular lymphocytic infiltration is not limited to metal-on-metal bearings. Clin Orthop Relat Res 2011;469:523-9. doi 10.1007/s11999-0101570-7

38. Wang Q, Eltit F, Garbuz D, Duncan C, Masri B, Greidanus N, Wang R. CoCrMo metal release in metal-on-highly crosslinked polyethylene hip implants. J Biomed Mater Res B Appl Biomater 2020;108(4):121328. doi:10.1002/jbm.b.34470

39. Perino G, Ricciardi BF, Jerabek SA, Martignoni G, Wilner G, Maass D, Goldring SR, Purdue PE. Implant based differences in adverse local tissue reaction in failed total hip arthroplasties: a morphological and immunohistochemical study. BMC Clin Pathol 2014;14:39. doi: 10.1186/1472-6890-14-39

40. Mishra PK, Palma M, Buechel B, Moore J, Davra V, Chu N, Millman A, Hallab NJ, Kanneganti TD, Birge RB, Behrens EM, Rivera A, Beebe KS, Benevenia J, Gause WC. Sterile particle-induced inflammation is mediated by macrophages releasing IL-33 through a Bruton's ty- rosine kinase-dependent pathway. Nat Mater 2019;18:289-97. doi: 10.1038/s41563-018-0271-6

41. Caicedo MS, Desai R, McAllister K, Reddy A, Jacobs JJ, Hallab NJ. Soluble and particulate Co-Cr-Mo alloy implant metals activate the inflammasome danger signaling pathway in human macrophages: a novel mechanism for implant debris reactivity. J Orthop Res 2009;27:847-54. doi: 10.1002/jor.20826

42. Radice $S$, Holcomb T, Pourzal R, Hallab NJ, Laurent MP, Wimmer $\mathrm{MA}$. Investigation of CoCrMo material loss in a novel bio-tribometer designed to study direct cell reaction to wear and corrosion products. Biotribology (Oxf) 2019;18:pii: 100090. doi: 10.1016/j. biotri.2019.100090

43. Vaculova J, Gallo J, Hurnik P, Motyka O, Goodman SB, Dvorackova J. Low intrapatient variability of histomorphological findings in periprosthetic tissues from revised metal/ceramic on polyethylene joint arthroplasties. Journal of biomedical materials research Part B Applied biomaterials 2018;106:2008-2018. doi: 10.1002/jbm.b.33990 